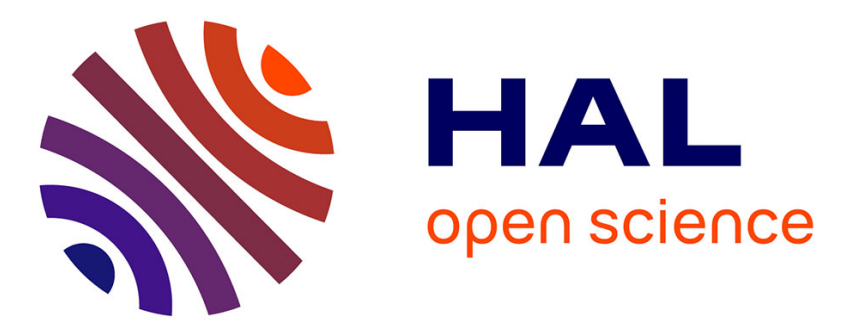

\title{
Study of melt flow dynamics and influence on quality for CO2 laser fusion cutting
}

\author{
A Riveiro, F Quintero, F Lusquiños, R Comesaña, J Pou
}

\section{To cite this version:}

A Riveiro, F Quintero, F Lusquiños, R Comesaña, J Pou. Study of melt flow dynamics and influence on quality for CO2 laser fusion cutting. Journal of Physics D: Applied Physics, 2011, 44 (13), pp.135501. 10.1088/0022-3727/44/13/135501 . hal-00606301

\section{HAL Id: hal-00606301 https://hal.science/hal-00606301}

Submitted on 6 Jul 2011

HAL is a multi-disciplinary open access archive for the deposit and dissemination of scientific research documents, whether they are published or not. The documents may come from teaching and research institutions in France or abroad, or from public or private research centers.
L'archive ouverte pluridisciplinaire HAL, est destinée au dépôt et à la diffusion de documents scientifiques de niveau recherche, publiés ou non, émanant des établissements d'enseignement et de recherche français ou étrangers, des laboratoires publics ou privés. 


\title{
STUDY OF MELT FLOW DYNAMICS AND INFLUENCE ON QUALITY FOR $\mathrm{CO}_{2}$ LASER FUSION CUTTING
}

\author{
A. Riveiro, F. Quintero, F. Lusquiños, R. Comesaña, J. Pou \\ Applied Physics Department, University of Vigo \\ ETSII, Lagoas-Marcosende, 9. Vigo, 36310, SPAIN
}

\section{ABSTRACT:}

The understanding of melt flow dynamics during fusion laser cutting is still a topic of great importance because this determines the quality characteristics of the processed workpiece. Despite the complexity of the experimental study of the physical processes involved in this technique, fusion laser cutting can be visualized during the processing of glass because this material absorbs the laser radiation provided by a $\mathrm{CO}_{2}$ laser but shows transparency to the visible radiation. Then, we present in this work the results of the study of the melt flow dynamics during laser cutting of glass. For different experimental conditions, the dynamics of the cutting front and its complete geometry (front wall inclination), and the evolution of the melt along the cut edge have been analysed by using a high speed video camera to study the process. It was found a phenomena no previously reported in the literature concerning to the ability of the plasma plume formed during the process. This can displace the normal shock wave (MSD) commonly formed in the inlet kerf being and can affect to the assist gas flow into the kerf.

On the other hand, the analysis of the recorded images allows determining the amount of molten material along the cut edge but also the direction and the velocity of the melt. Relevant processing parameters affecting to the flow of molten material were assessed. These results are used as a basis to explain the different processes involved in the generation of dross, a typical imperfection appeared in laser cutting. 


\section{INTRODUCTION}

Laser cutting is one of the most widespread applications of lasers and a wellestablished and effective method of cutting a wide range of materials, mainly metals. Different variants of the laser cutting technology involve (I) inert-gas fusion cutting, (II) reactive-gas fusion cutting (III) vaporization cutting, (IV) scribing and, (V) controlled fracture (1). However, the preferred techniques to cut metals are inert-gas or reactivegas fusion cutting processes. These are based on the simultaneous and coaxial action of a high-intensity laser beam and an inert or reactive gas jet onto the workpiece.

In this process, the laser beam melts the workpiece along its full depth and produces a cutting front which travels through the workpiece. The material on the cutting front is partially melted and evaporated by the laser beam, and then removed by the assist gas jet from the cut slot. This technique involves multiple and interdependent physical processes that affect the laser cutting results. Among others we can cite, the beam absorption in the cutting front (which depends on the laser wavelength, the temperature of the melt, the presence of oxides, the polarization state of the laser radiation, etc.), the fluid dynamics of the assist gas and the melt flow, the oxidation reaction of the melt, etc. (2-6). The practice of laser cutting posses a number of basic problems; one of the most important is the understanding of the reasons for defect formation (such as dross) and its suppression. This fact becomes essential for cutting some materials for demanding applications. Theoretical predictions of the laser cut quality is very complicated, requiring complex and sophisticated modelling approaches due to the great variety of parameters involved. For this reason, an experimental evaluation of the specific conditions of laser cutting of each material is needed to optimize the results in terms of cut quality.

An alternative and complementary approach to modelling is the visualization of the process. There are quite a few precedents to the visualization of laser cutting due to the intrinsic difficulties of filming a hot melt moving at high speed. First filming studies of laser cutting were conducted by the group of Prof. Yoshiaki Arata at Osaka University, Japan in the late 1970's (7, 8). They observed the cutting front with the aid of high-speed imaging during the $\mathrm{CO}_{2}$ laser cutting of mild steel using oxygen. They observed the cutting front normally (at an angle of $30^{\circ}$ downwards to the workpiece surface) and complemented these results also filming the lateral motion of the cutting front by cutting in the workpiece edge. They found that cyclical combustions occurred 
faster than by the direct action of the laser beam for low cutting speeds resulting in the formation of striations. However, the melt flow along the cut edge was not considered in their work; in fact, the understanding of this feature is essential to determine the resulting cut quality of the cut edge. On the other hand, the experimental arrangement of cutting in the workpiece edge is somehow unrealistic.

Poprawe and König (9) visualized the cutting process using a CCD camera coaxial to the laser beam for monitoring and control purposes. The motion of the melt was monitored but could not be resolved during the flow along the cutting edge. Yudin and Kovalev (10) observed laterally the process by cutting along the workpiece edge of a low melting point alloy sheet and putting a glass sheet to simulate the process in a more realistic way than the early work of Prof. Arata. They visualized the cutting front and the striation structure. However, they were cutting two different materials at the same time to be able to simulate the cutting process. In all these studies there is a lack of a detailed investigation on the dynamics of the melt flow, especially studies designed to reveal how the processing parameters affect to the motion of the molten material and to the cut quality results, such as dross formation.

The objective of this work is the visualization of the laser cutting process of glass in continuous wave $(\mathrm{CW})$ mode (i.e.: the energy provided by the laser beam is kept constant with time). The first part of this paper is devoted to the visualization of the cutting process and to the description of the relationship between the main processing parameters and the cutting front dynamics and melt flow pattern along the cut edge. A comprehensive survey of the phenomena occurred during laser fusion cutting is presented because the understanding of this feature is essential to determine the resulting cut quality. In the second part, we will establish the mechanism that explains how the dross is formed according to the different melt flow patterns previously described. These results are discussed taking into account the physical mechanisms governing the process and an insight, based on a similarity approach, on the possible transfer of the obtained results to the process of laser cutting of metals has been provided. 


\section{EXPERIMENTAL SETUP}

The experimental set-up used for the experiments is shown in Fig. 1a. All experiments were performed with a $3.5 \mathrm{~kW} \mathrm{CO}$ slab laser (Rofin-Sinar), the laser mode being a TEM $\mathrm{T}_{00}$. The laser beam was focused onto the surface of the workpiece using a $127 \mathrm{~mm}$ focal length lens. Tests were conducted in continuous wave $(\mathrm{CW})$ and varying one factor at a time. The ranges of cutting parameter are summarized in Table 1. A commercial cutting head incorporating a conical converging coaxial nozzle with a $2 \mathrm{~mm}$ exit diameter was used to supply the assist gas jet into the interaction zone. Argon was used as inert assist gas.

In order to visualize the cutting process, we have followed a similar approach to that described by Arata et al. $(\mathbf{1 1}, \mathbf{1 2})$ and Jin and Li $(\mathbf{1 3})$ to observe the keyhole shape during laser deep penetration welding. As depicted in Fig. 1, we have used a soda-lime silicate glass of the 'float glass' type, $6 \mathrm{~mm}$ thick, as workpiece. This material strongly absorbs the laser radiation emitted by the $\mathrm{CO}_{2}$ laser but is transparent to the visible radiation; therefore, a realistic and very clear picture of the process can be obtained. The survey was performed using a CMOS fast camera (Photron FASTCAM-1024 PCI) recording at 10,000 frames per second, a shutter speed of 1/402000 s, and with contrast illumination using a halogen lamp behind the sample faced towards the camera. The maximum resolution achieved was $128 \times 272$ for this frame rate. The camera was placed about $180 \mathrm{~mm}$ from the workpiece and positioned in the transverse direction to the cutting direction, as represented in Fig. 1a, to observe the behaviour of the cutting front and the flow of molten material along the cutting edge. In order to record fine details of the cutting process a macro objective (Sigma EX DG Macro) with a F2.8 maximum aperture was used.

The camera was connected to a PC in order to record and process the images of the cutting procedure. The influence of the processing parameters on the cutting front geometry was determined by means of the evaluation of the cutting front inclination (see Fig. 1b). The slope of the cutting front was assessed in several points and a mean inclination was calculated. On the other hand, two main parameters were evaluated to characterize the flow of molten material along the cutting edge in selected images of the process: the flow direction and the extension of the molten material flowing along the 
cut edge. These parameters were measured using the free image processing and analysis software ImageJ on selected frames in recorded high-speed videos.

\section{RESULTS AND DISCUSSION}

\subsection{CUTTING FRONT GEOMETRY}

Fig. 2 shows the typical aspect of the cut kerf during the laser cutting process. As can be observed, the profile of the cutting front does not match that of the laser beam. This becomes curved in the lower part depending on the processing parameters. As depicted in Fig. 2b, and quantified in Table 2, the cutting front exhibits a larger curvature when the cutting speed is increased, mainly, in the lower part. Due to the fact that the laser beam was focused close to the surface of the workpiece, the irradiance in the lower part of the cutting front is lower than in the upper part, resulting in a curved profile. The observed dependence of the cutting front inclination is in good agreement with theoretical predictions reported in the literature $(\mathbf{1 4}, \mathbf{1 5})$. However, additional influences on the inclination, not considered in previous works, were observed. As summarized in Table 2, cutting front inclination also depends on the laser power, cutting speed, and on the assist gas pressure. In order to take into account the combined action of the laser power and cutting speed we have used the linear energy density. The inclination of the cutting front is seen to increase when the linear energy density decreases (see Table 2). However, an increase of the assist gas pressure increments the inclination probably due to the energy losses consequence of the higher removal of molten material.

\subsection{MOLTEN MATERIAL DYNAMICS}

The interaction of the laser beam with the cutting front produces a thin film of molten material as observed in Fig. 2a. The high brightness of this melt indicates the superior temperature in this region. The melt is subjected to the removal action of the assist gas by means of two mechanisms: the pressure gradient and the shear stress along the cutting front. Both mechanisms tend to remove the molten material in a direction 
parallel to the cutting front (Z-direction as depicted in Fig. 2) (2). On the other, hand, as observed in Fig. 2a, the thickness of this film is not uniform, probably as a consequence of Kelvin-Helmholtz instabilities produced by the high speed assist gas stream adjacent to the molten film (16).

In laser cutting, the laser beam has enough irradiance, typically in a range from $10^{6}$ to $10^{8} \mathrm{~W} / \mathrm{cm}^{2}$ to partially evaporate the material on the cutting front $(\mathbf{1}, \mathbf{1 7})$. Therefore, the vapour is ejected perpendicularly to the surface of this cutting front. Evaporation produces a uniform pressure on the molten material generated in cutting front; this action, so-called recoil pressure $\left(\mathrm{p}_{\mathrm{s}}\right)$, depends on the temperature of the molten material according to the Eq. (1) (18):

$$
p_{s}=A \frac{B_{0}}{\sqrt{T_{s}}} \exp \left(-\frac{m_{v} L_{v}}{k_{B} T_{s}}\right)
$$

where A is a factor which depends on the ambient pressure, B is an evaporation constant, $\mathrm{T}_{\mathrm{s}}$ the temperature of the molten material on the cutting front, $\mathrm{m}_{\mathrm{v}}$ the mass of the vapour molecule, $\mathrm{L}_{\mathrm{v}}$ the latent heat of vaporization and $\mathrm{k}_{\mathrm{B}}$ the Boltzmann constant.

The recoil pressure ejects the molten material along the cut edge in a direction perpendicular to the cutting front (Y-direction) in Fig. 2. As shown in Fig. 3, flow streams ejected from the cutting front, and with higher temperature than the rest of the melt, flow along the cut edge. Occasionally, the molten material is accelerated from the cutting front after an energetic explosion, probably due volumetric evaporation into the melt (see Fig. 4) (19).

The velocity of the molten material ejected from the cutting front was estimated using the bright flow streams periodically ejected from the cutting front (as seen in Fig. 3). Several measurements were accomplished and an average value was extracted and assumed to be the flow velocity of the molten material. The ejection velocity of molten material from the cutting front by the recoil pressure was found to depend on the processing conditions because, as shown in Eq. (1), this force depends on the temperature of the molten material. Furthermore, this velocity varies as a function of the studied region in the cutting front. This indicates the existence of differences in the temperature as a function of the considered region of the cutting front. Under all tested processing conditions, the molten material generated in the upper part of the cutting front is mainly dragged downwards by the assist gas. In this part of the cutting front the effect of the recoil pressure is surpassed by the action of the gas. On the opposite, the 
recoil pressure in the lower part of the cutting front is higher. This is in accordance with the predicted increment in temperature in the lower part of the cut front which, in turns, produces a more intense evaporation regime $(\mathbf{2 0}, \mathbf{2 1})$. Flow velocities of molten material around $\mathrm{v}_{\mathrm{y}}=500 \mathrm{~mm} / \mathrm{s}$ estimated for a laser power of $\mathrm{P}=1400 \mathrm{~W}$ and a cutting speed of $\mathrm{v}_{\mathrm{c}}=500 \mathrm{~mm} / \mathrm{min}$. However, if the cutting speed is increased to $\mathrm{v}_{\mathrm{c}}=1000 \mathrm{~mm} / \mathrm{min}$, the ejection velocity rises up to $\mathrm{v}_{\mathrm{y}}=2300 \mathrm{~mm} / \mathrm{s}$. The dependence of the ejection velocity with the cutting speed is a consequence of the predicted increment in the cutting front temperature with the cutting speed $(\mathbf{1 4}, \mathbf{2 2})$ which promotes a more intense evaporation and therefore a higher recoil pressure as deduced from Eq. (1) (18). On the other hand, the ejection velocity was also revealed to be dependent on the laser power, being increased with this parameter also due to the increment in the temperature and evaporation intensity.

Finally, the analysis of the processes does not reveal cyclic combustion waves in the cutting front as in the process of laser cutting of steel using oxygen (see for example Refs. (23-25)) because the assist gas cannot produce a further oxidation on the molten glass

\subsection{FLOW OF MOLTEN MATERIAL ALONG THE CUT EDGE}

After being ejected backwards by the recoil pressure (in the Y-direction), the molten material flows along the cut edge only subjected to the sweeping action of the assist gas. Then, the direction of the main force acting on the melt changes and the gas propels the melt in a direction almost parallel to the cutting front (Z-direction) because the gas flow in the kerf is inclined. As described by Kovalev et al. (26), the streamlines for the assist gas are substantially deflected from the nozzle centreline into the kerf due to the interaction of the jet with the cutting front. Furthermore, the use of a converging coaxial nozzle can induce the phenomenon of gas flow separation from the cut front and the formation of a reverse flow into the kerf (26-29). This produces a significant decrease in the flow velocity of the assist gas and a reduction in the removal of molten material by the gas.

If the melt is not completely extracted by the assist gas from the cut kerf, it will solidify on the cut edge resulting in cuts with poor finishing and a noticeable heat affected zone (HAZ). An interesting parameter to determine the ability of the gas to remove the molten material from the cut edge is the extension of molten material 
flowing along it. As expected, the longer the extension of molten material on the cut edge, the poorer the surface finishing of the cut edge due to the higher tendency to the presence of resolidified material, dross and a large HAZ. Experimental tests allow us to determine the influence of processing parameters on the extension of the molten material flowing along the cut edge (see Table 3). In one hand, the extension is increased with the laser power because the rate of melting is higher and the ejection backwards the cutting front due to the high recoil pressure too. Then, these actions surpass the reduced removal of molten material by the assist gas, consequence of its separation from the cutting front. Also it is noticed that the extension of molten material is increased with the cutting speed, probably due to two reasons. First, the rate of melting is promoted by the heat conduction loses which rise with the cutting speed (14, 30); second, the higher temperatures reached on the cutting front, when the cutting speed is increased, produces a more intense evaporation (14). Consequently, the higher recoil pressure expels more molten material backwards the cutting front. Combined action of these effects promotes a larger amount of molten material on the cut edge (for a constant removal action of the assist gas). This generates cuts with poor finishing because the amount of resolidified material will be larger.

On the other hand, visualization results confirm the primary role of the assist gas on the process. The increment of the assist gas pressure tends to remove a larger amount of molten material and confine it too near to the cutting front. Hence, the amount of resolidified material decreases and the cut quality is improved as experimentally confirmed in cutting different materials (see for example Ref. (31)). However, it is necessary to considerer the increment in the strength of the normal shock wave produced with the increment in the assist gas pressure. As observed in Fig. 5a by means of shadowgraph imaging, a normal shock wave, called Mach Shock Disk (MSD), is formed on the workpiece, principally, as consequence of the normal impingement of the jet and due to the superior dimensions of the jet as compared to the cut slot. This shock wave is a discontinuity that reduces the velocity of the gas and, in consequence, the removal of molten material. As observed in Fig. 5b, the increment in the stand-off distance decreases the normal shock wave but increases the extension of molten material on the cut edge. Despite several works explain the formation of this normal shock wave and the consequences of this phenomenon on the removal of molten material during laser cutting, this is the first report of experimental observation of this phenomenon during a real laser cutting process. 
On the other hand, as observed in Figs. 3 and 5, the vaporized material in the cutting front becomes ionized and a plume of plasma emerges from the upper face of the workpiece. Despite, the experimental tests were performed in $\mathrm{CW}$ mode, the plasma plume exhibits a periodic nature as clearly depicted in Fig. 3. Experiments show that at low assist gas pressure ( $\mathrm{p}=3$ bar), the plume is generated and disappears, whereas at higher pressures ( $\mathrm{p}=8$ bar) the plume is constantly present, but the height of the plume fluctuates. In both cases, the frequency of ignition-extinction and the oscillation in height was found to be around $\mathrm{f}=680 \mathrm{~Hz}$ under the tested processing conditions. The influence of the assist pressure on the plume dynamics can be attributable to the swirls generated in the upper face of the workpiece due to the normal impingement of the jet. These swirls produce a higher exposition time of the assist gas to the laser radiation and to the vaporization products formed in the cut kerf; therefore, the trend to ionization is increased resulting in a constant presence of the plasma plume. This non-periodic nature of the plume indicates the unsteady character of the laser cutting in $\mathrm{CW}$; this must be considered a quasi-steady process. On the other hand, it was found that the plasma plume is able to displace the MSD up to $140 \mu \mathrm{m}$ as depicted in Fig. 6.

This conclusion was corroborated observing the non-oscillatory character of the shock wave when the laser radiation was interrupted. As observed in Fig. 7, the position of the MSD remains stable when the cutting process stops and the laser beam does not interacts with the cutting front. Hence, despite the unsteady behaviour of an impinging jet flow structure (see for example Refs. $(\mathbf{3 2}, \mathbf{3 3})$ ), the imperceptible deviation in the position of the normal shock wave with regard to the workpiece when the laser is interrupted confirms the primary role of the plasma plume on the motion of the shock.

This fact, no previously reported in the literature, makes the MSD to oscillate with the same frequency than the plasma. Despite it is asserted that the effect of plasma is negligible in CW mode cutting (34), this oscillation of the plume can affect to the dynamics of the assist gas into the cut kerf because the shock wave pattern inside the cutting kerf is modified. Moreover, the separation point of the assist gas can fluctuate with this frequency. Therefore, this can affect the removal of molten material by the gas, inducing periodic oscillations on the flow of molten material along the cut edge and cutting front which could explain some unsolved questions regarding the striation formation during laser cutting using inert gases.

Analysis of recorded images also indicates that the flow direction of the molten material along the cut edge takes place at an angle of $\theta=30-50^{\circ}$ with respect to the 
cutting front depending on the assist pressure. At low gas pressure ( $p=3$ bar in this work), the molten material flows at an angle of $\theta=50^{\circ}$ (see Fig. 8a); however, if the supplying pressure is higher ( $\mathrm{p}=8 \mathrm{bar}$ ), the molten material flows with less inclination, at an angle of $\theta=30^{\circ}$ (see Fig. 8b). This modification in the trajectory reduces the amount of melt flowing along the cut edge and the thermal input to the workpiece. This is the reason of the improvement in cut quality experienced during the increase in the assist gas pressure, as corroborated by different authors $(\mathbf{3 1}, \mathbf{3 5})$.

It is necessary to take into account the influence of the laser power on the flow velocity of molten material along the cut edge. A detailed survey of the process reveals a faster motion of the molten material for high laser power as summarized in Table 4. The increment in the laser power makes more fluid the melt due to the reduction of the kinematic viscosity with the temperature; hence, this is removed at higher rate by the assist gas. On the other hand, the increment in the assist gas pressure also promotes the removal of molten material; as reported in Table 4, the flow velocity of molten material along the cut edge increases with the pressure because the viscous friction and the pressure gradient arise (2). In summary, an increment in the assist gas pressure is necessary to remove a larger amount of molten material although it is also necessary a minimum laser power to make it enough fluid.

Finally, behind the region of molten material on the cut edge is a quasi-solidified layer of molten material. This material is part of the molten material which previously was flowing along the cut edge and was not removed by the assist gas. This material flows at low velocity due to its high viscosity and its location at a region of the cut edge too far from the direct action of the assist gas. The analysis of the recorded images reveals a velocity flow around $4.5 \mathrm{~mm} / \mathrm{s}$ for a laser power of $800 \mathrm{~W}$, a cutting speed of $500 \mathrm{~mm} / \mathrm{min}$, and an assist pressure of 8 bar. It is worth to compare this velocity with that of the molten material under the same processing conditions (see Table 4) which is approximately 25 times higher. This suggests that the cooling of the molten material makes very difficult to completely remove it from the cut edge and obtain clean cuts. Therefore, it is very important to remove the molten material as soon as possible from the cut edge or avoid as much as possible a high extension of molten material on the cut edge to obtain cuts with good quality (low HAZ, low dross and low resolidified material). 


\subsection{DROSS FORMATION}

Dross formation is one of the typical imperfections generated on the cut edges. The process is a consequence of the agglomeration of molten material which flows along the cut edge in the lower wedge of it. The sequence of images presented in Fig. 9 reveals the formation process of this imperfection. As observed, a drop of molten material is generated in the lower part of the cutting front by the molten material flowing along the cut edge. The drop size is higher as more molten material arrives. On the other hand, the previously cited separation of the assist gas flow from the cutting front, produces a thin film of molten material flowing along the cut edge. This film induces the formation of more drops behind the drop previously formed near to the cutting front (see Fig. 10). Then, these drops can merge. The drop closer to the cutting front was seen to move in a direction contrary to the cutting front propagation probably due to the surface tension gradients induced by the temperature gradient. Due to the fact that the temperature diminishes along the trailing edge of the cut edge, backwards the cutting front, the lower surface tension in the hot surface of the molten material near to the cutting front pulls the liquid backwards the cutting front to the cold region.

It is worth to mention that the motion of the drop is more probably produced due to surface tension gradients than to the action of $\mathrm{Y}$-component of the assist gas, because the analysis of the images depicted in Fig. 10 reveals a slow motion of the drops. The velocity of these were estimated by means of the analysis of the images. An average value of the velocity around $0.03-0.6 \mathrm{~m} / \mathrm{s}$ was found. However, the Y-component of the assist gas, which may produce this motion of the drop, can be estimated around $V_{0} \cos \varphi=40-170 \mathrm{~m} / \mathrm{s}$ (being $\mathrm{V}_{0}$ the average velocity of the assist gas and $\varphi$ the deflection of the gas jet with regard to the nozzle centreline). This velocity was estimated taking into consideration an average value $\mathrm{V}_{0}=340 \mathrm{~m} / \mathrm{s}$ for the gas jet and an inclination of the gas similar to that of the cutting front inclination ( $\varphi$ varying from $6.5^{\circ}$ up to $30,4^{\circ}$ as reflected in Table 2). A simple comparison of the orders of magnitude suggests that the motion of the drop should be faster if it is a direct consequence of the Y-component of the assist gas. Then, it is probably consequence of surface tension gradients. 
While the drops are solidifying, they are subjected to the shear action of the gas which can induce three main processes on them: deformation, breaking-up or detachment. The occurrence of each phenomenon primarily depends on the Weber number (We) for the drop (36), which is a measure of the relative importance of the fluid's inertia $\rho \mathrm{u}_{\mathrm{m}}{ }^{2}$ as compared to the counteracting capillary pressure $\sigma / \mathrm{d}$ :

$W e=\frac{\rho(T) u_{m}^{2}(T) d}{\sigma(T)}$

where, $\rho(T)$ is the density of the molten material at the corresponding temperature in the cut edge, $u_{m}(T)$ the velocity of the molten material induced by the shear action of the gas (which depends on the value of the viscosity of the molten material at the corresponding temperature in the cut edge), $d$ the drop diameter and $\sigma(T)$ the surface tension of the molten material at the corresponding temperature in the cut edge.

If the capillary forces become comparable with the inertia of the melt $(\mathrm{We} \approx 1)$, the separation of melt flow from the lower part of the cutting front is not total and tendency to dross formation is very high. The appearance of dross is related to small values of the Weber number. In order to have dross free cuts, the Weber number of the melt, in the lower part of the cutting front, must exceed some critical value. The values for the critical Weber number available from the literature are scattered over a very wide range of We from 2.2 to 99.6. (37). However, it is generally agreed that the minimum critical Weber number increases with the viscosity of the drop; this dependence is usually expressed through the Ohnesorge number:

$O h=\mu / \sqrt{\rho \sigma d}$

where, $\mu$ is the viscosity of the molten material at the corresponding temperature in the cut edge (38). Then, as the viscosity of the melt increases, while the molten material is solidifying, the momentum that the assist gas transfers to the melt must be very high to break up the drop and produce dross free cuts.

For Weber numbers in a range from the unit to the critical value, the drop only tends to be deformed and elongated and can be partially break up. Under this regime, the presence of dross is also constant.

The visualization of the dross formation process, under different processing conditions, reveals that the predominance of these processes primarily depends on the distance of the drop on the cut edge to the cutting front. This is because the molten material is hotter when is nearer to the cutting front than in positions far away from it. 
Thus, the physical properties, namely, the viscosity, density, surface tension and consequently the velocity of the melt, vary as a function of the position of the drop on the cut edge. Finally, the variation of these properties modify the Weber number of the melt in different locations of the lower part of the cut edge. It is expected that near to the cutting front, the higher temperature of the melt increases the Weber number because the velocity of the melt is higher (due to its lower viscosity) and the surface tension is lower. Therefore, the molten material tends to be broken-up (see Fig. 11) and small droplets can be formed as observed in Fig. 12. This process, primarily occurring near to the cutting front, produces small particles with different size. This process can be identified as the main responsible for the well-known formation of micro-particles, observed during laser cutting of steel, ranging from 70 to $400 \mu \mathrm{m}$ during laser cutting (39).

On the other hand, far from the cutting front, the lower velocity of the melt (due to the higher viscosity) and the higher surface tension makes the value Weber number very low. Then, the molten material principally tends to be elongated as observed in Fig. 9 and the presence of dross is persistent.

From these results we can assert that the separation of the assist gas from the cutting front, which produces a film of melt along a large area on the cut edge, tends to produce dross because the molten material far away from the cutting font has Weber number close to the unit. Therefore, we must confine the molten material near to the cutting front in order to have a melt with large Weber numbers and to obtain dross free cuts. An option to produce this confinement is promoting the impact of the assist gas jet onto the cutting front being as close to $90^{\circ}$ as possible. Therefore, the assist gas jet should be injected by means of an oblique nozzle with regard to the laser beam.

\subsection{COMPARISON TO METAL CUTTING}

Finally a question on similarities can be arisen. Despite the results presented in this paper have been focussed on the laser cutting of glass, some common features with the process of cutting metals are evident. As observed in the cut edges depicted in Fig. 13, a clear parallelism between the cut characteristics of metals and glass can be draw. Both kinds of materials exhibit common features such as the generation of striations and dross. The extension of results can be roughly done by means of the comparison of the thermophysical properties of metals and glass, namely the following: 
1. Despite metals have a smaller absorption length as compared to glasses, metals can compensate this by a much higher thermal conductivity (for example, the thermal conductivity of soda lime glass is $\mathrm{k}_{\mathrm{g}}=1.7 \mathrm{~W} / \mathrm{mK}$, while for typical metals such as aluminium is $\sigma_{\mathrm{al}}=247 \mathrm{~W} / \mathrm{mK}$ and for steels $\sigma_{\mathrm{s}}=52 \mathrm{~W} / \mathrm{mK}(\mathbf{4 0})$ ). Then, the order of magnitude of the molten material generated in the cutting front by the action of the laser beam would be similar.

2. Furthermore, the high viscosity of the molten glass, which embarrasses the ejection of the molten material from the kerf, is also observed when metals cutting. Although metals have a small viscosity, their high thermal conductivity produces a rapid cooling of the molten material and consequently an increment in their viscosity; this being comparable, up to certain extent, to the case of cutting glass.

3. However, the smaller viscosity of metals as compared to glass (neglecting the influence of the thermal conductivity), induces lower Reynolds numbers for glass $R e_{g}=\frac{\rho_{g} u_{g} d}{\mu_{g}}$ (where $\rho$ is the density, $\mathrm{u}$ the flow velocity, $\mathrm{d}$ a characteristic dimension and $\mu$ the dynamic viscosity of the molten material and the subscript $\mathrm{g}$ refers to glass) than for metals $R e_{m}=\frac{\rho_{m} u_{m} d}{\mu_{m}}$ (the viscosity of glasses ranges from $\mu_{\mathrm{g}}=10^{5}$ to $10^{9} \mathrm{P}$ while for metals ranges from $\mu_{\mathrm{m}}=10^{-3}$ to $10^{-1} \mathrm{P}$ ). Therefore, the turbulent characteristics of the flow of molten material should be more pronounced in the case of cutting metals than glass because the Reynolds number will be, in principle, higher during the processing of metals than glass. This assertion can be roughly validated comparing the more turbulent flow of molten material observed during laser cutting of metals (see for example Refs. (7-10)) than in the case of cutting glass, as previously presented.

4. On the other hand, the surface tension of soda-lime glass is one order of magnitude lower than metals (for example, the surface tension of soda lime glass is $\sigma_{\mathrm{g}}=315 \mathrm{mN} / \mathrm{m}$ at $1573 \mathrm{~K}$, while for typical metals such as aluminium is $\sigma_{\mathrm{al}}=1070 \mathrm{mN} / \mathrm{m}$ at $933 \mathrm{~K}$ and for iron $\sigma_{\mathrm{fe}}=1900 \mathrm{mN} / \mathrm{m}$ at $1573 \mathrm{~K}$ ). Then, the Weber number for glass $W e_{g}=\frac{\rho_{g} u_{m}^{2} d}{\sigma_{g}}$ is lower than for metals $W e_{m}=\frac{\rho_{m} u_{m}^{2} d}{\sigma_{m}}$ because the density of glasses and metals have the same order of magnitude (for 
example, the density of soda lime glass is $\rho_{\mathrm{g}}=2.5 \mathrm{~g} / \mathrm{cm}^{3}$, while for typical metals such as aluminium is $\rho_{\mathrm{al}}=2.7 \mathrm{~g} / \mathrm{cm}^{3}$ at $933 \mathrm{~K}$ and for mild steel and stainless steel $\rho_{\text {msteel }}=7.85 \mathrm{~g} / \mathrm{cm}^{3}, \rho_{\text {ssteel }}=8.03 \mathrm{~g} / \mathrm{cm}^{3}$ respectively). Then, the lower Weber number of glasses as compared to that of metals indicates a higher tendency for the deformation of the molten droplets. This can be corroborated by the elongated character of the dross as compared to the less pronounced dross present in the case of metals. Therefore, this is the main difference between dross formation for metals and glass; however, the general overview of the process observed in this work for glass could be transferred to metal cutting.

In summary, most of the results obtained in this paper, regarding the physical mechanisms governing the flow of molten material and the dross formation, should be valid for metal cutting under certain restrictions.

\section{CONCLUSIONS}

Fundamental phenomena during high power $\mathrm{CO}_{2}$ laser cutting of glass were dynamically observed and the flow of molten material during the process was analysed. Furthermore, the influence of the flow of molten material on the quality results, mainly, the formation of dross during the process, was dynamically assessed.

The visualization experiments were performed during laser cutting of glass because the material strongly absorbs the $10.6 \mu \mathrm{m}$ laser radiation but it is transparent to the visible radiation. Then, it is possible to clearly observe the process.

The main conclusions from the visualization experiments can be summarized as follows:

(i) The cutting front geometry varies as a function of the processing parameters in order to balance the different energy contributions.

(ii) The material melted in the cutting front was seen to flow along the cut edge. The recoil pressure ejects the molten material backwards the cutting front. The intensity of the force depends on the temperature of the cutting front. Estimations on the ejection velocity of the molten glass were provided by means of image analysis. 
(iii) After being ejected, the molten material flows along the cut edge at an angle of $30^{\circ}-50^{\circ}$ with regard to the cutting front. The flow pattern also depends on the processing conditions. The assist gas pressure was seen to reduce the amount of molten material flowing along the cut edge. However, the intensity of the MSD was seen to increase.

(iv) The plume of ionized material was observed to oscillate with a frequency around $680 \mathrm{~Hz}$. An interesting issue is that, these oscillations can produce variations on the position of the MSD which will affect to the assist gas flow into the kerf and to the removal of molten material. This result has a strong relevance during high pressure laser cutting.

(v) The formation of dross was seen to be a cyclical process. A drop of molten material is formed in the lower wedge of the cut edge. If the shear action of the gas is not able to detach the drop, this can solidify producing cuts with dross.

(vi) The detachment of the drop, and in consequence the obtaining of dross free cuts, was seen to occur at a critical Weber number. Large Weber numbers ensures the detachment of the molten material.

(vii) The process of dross generation was seen to be amplified by the flow of a large amount of molten material on the cut edge.

(viii) As the Weber number of the drops vary as a function of the distance from the cutting front due to the variation on the temperature of the molten material, different phenomena takes place. Near to the cutting front, drops tend to breakup producing the particulate emissions typical in laser cutting. However, drops far from the cutting front tend to be elongated due to the higher viscosity of the molten material.

Finally, under a basis of similarity analysis it is suggested that the results obtained in this work could be transferred, up to certain extent, to the laser cutting of metals.

\section{ACKNOLEDGEMENTS}

The authors wish to thank to technical staff from CACTI (University of Vigo) for his help with sample characterization. This work was partially supported by the Spanish 
Government, (CICYT MAT2006-10481 and FPU program AP2006-03500 grant), and by Xunta de Galicia (PGIDIT05TMT30302PR, PR405A2002/11-0, INCITE081R303002ES and INCITE08PXIB303225PR). 


\section{REFERENCES}

1. Steen WM. Laser material processing. $3^{\text {rd }}$ ed. London; New York: Springer; 2003.

2. Vicanek M, Simon G. Momentum and heat transfer of an inert gas jet to the melt in laser cutting. Journal of Physics D: Applied Physics. 1987;20(9):1191-96.

3. Baeva M, Kaplan AFH. An analysis of the heat transfer from a moving elliptical cylinder. Journal of Physics D: Applied Physics. 1997;30(8):1190-96.

4. Niziev VG, Nesterov AV. Influence of beam polarization on laser cutting efficiency. Journal of Physics D: Applied Physics. 1999;32(13): 1455-1461.

5. Kovalev OB, Zaitsev AV. Modeling of the free-surface shape in laser cutting of metals. 2. Model of multiple reflection and absorption of radiation. Journal of Applied Mechanics and Technical Physics. 2005;46(1):9-13.

6. Quintero F, Varas F, Pou J, Lusquiños F, Boutinguiza M, Soto R, Pérez-Amor M. Theoretical analysis of material removal mechanisms in pulsed laser fusion cutting of ceramics. Journal of Physics D: Applied Physics. 2005;38(4):655-66.

7. Arata Y, Maruo H, Miyamoto I, Takeuchi S. Dynamic behaviour in laser gas cutting of mild steel. Transactions of JWRI. 1979 1979-12;8(2):175-86.

8. Arata Y, Maruo H, Miyamoto I, Takeuchi S. Quality in laser-gas-cutting stainless steel and its improvement. Transactions of JWRI. 1981 1981-12;10(2):129-39.

9. Poprawe R, König W. Modeling, Monitoring and Control in High Quality Laser Cutting. CIRP Annals - Manufacturing Technology. 2001;50(1):137-40.

10. Yudin P, Kovalev O. Visualization of events inside kerfs during laser cutting of fusible metal. Journal of Laser Applications. 2009;21(1):39-45.

11. Arata $\mathrm{Y}$, Abe N, Oda T. Fundamental phenomena in high power $\mathrm{CO}_{2}$ laser welding (Report I): Atmospheric laser welding. Transactions of JWRI. 1985;14(1):5-11.

12. Arata $\mathrm{Y}, \mathrm{Abe} \mathrm{N}$, Oda T. Fundamental phenomena in high power $\mathrm{CO}_{2}$ laser (Report II) : Vacuum laser welding. Transactions of JWRI. 1985;14(2):217-22.

13. Jin X, Li L. An experimental study on the keyhole shapes in laser deep penetration welding. Optics and Lasers in Engineering. 2004;41(5):779-90.

14. Kaplan AFH. An analytical model of metal cutting with a laser beam. Journal of Applied Physics. 1996;79(5):2198-208.

15. Kaplan AFH. Theoretical analysis of laser beam cutting. Aachen: Shaker Verlag $\mathrm{GmbH} ; 2002$. 
16. Craik ADD. Wind-generated waves in thin liquid films. Journal of Fluid Mechanics. 1966;26(02):369-92.

17. Bäuerle D. Laser processing and chemistry. $3^{\text {rd }}$ ed. Berlin ; New York: Springer; 2000.

18. Semak V, Matsunawa A. The role of recoil pressure in energy balance during laser materials processing. Journal of Physics D: Applied Physics. 1997;30(18):2541-52.

19. Von Allmen M, Blatter A. Laser-beam interactions with materials: physical principles and applications. $2^{\text {nd }}$ ed. Berlin ; New York: Springer; 1995.

20. Olsen FO, Alting L. Cutting front formation in laser cutting. CIRP Annals Manufacturing Technology. 1989;38(1):215-8.

21. Olsen FO. Fundamental mechanisms of cutting front formation in laser cutting. Proceedings of SPIE. 1994;2207:402-13.

22. Mas C, Fabbro R, Gouedard Y. Steady-state laser cutting modeling. Journal of Laser Applications. 2003;15(3):145-52.

23. Miyamoto I, Maruo H. Mechanism of laser cutting. Welding in the World, Le Soudage Dans Le Monde. 1991;29(9-10):283-94.

24. Arata Y, Maruo H, Miyamoto I, Takeuchi S. Dynamic Behavior in Laser Gas Cutting of Mild Steel Transactions of JWRI. 1979;8(2):175-86.

25. Yudin P, Ermolaev G, Verna E, Jouanneau T. Visualization and modelling of combustion effects at laser cutting of mild steel with oxygen. Proc. $4^{\text {th }}$ Pacific International Conference on Applications of Lasers and Optics PICALO 2010; March 23-25; Wuhan 2010.

26. Kovalev OB, Yudin PV, Zaitsev AV. Modeling of flow separation of assist gas as applied to laser cutting of thick sheet metal. Applied Mathematical Modelling. 2009;33(9):3730-45.

27. Zefferer H, Petring D, Beyer E. Investigations of the gas flow in laser beam cutting. Proc 3rd Int Conf Strahltechnik. 1991:210-4.

28. Man HC, Duan J, Yue TM. Analysis of the dynamic characteristics of gas flow inside a laser cut kerf under high cut-assist gas pressure. Journal of Physics D: Applied Physics. 1999;32(13):1469-77.

29. Chen K, Yao YL, Modi V. Gas jet-workpiece interactions in laser machining. Journal of Manufacturing Science and Engineering, Transactions of the ASME. 2000;122(3):429-38. 
30. Schulz W, Becker D, Franke J, Kemmerling R, Herziger G. Heat conduction losses in laser cutting of metals. Journal of Physics D: Applied Physics. 1993;26(9):135763.

31. Riveiro A, Quintero F, Lusquiños F, Comesaña R, Pou J. Parametric investigation of $\mathrm{CO}_{2}$ laser cutting of 2024-T3 alloy. Journal of Materials Processing Technology. 2010;209(10):1138-52.

32. Ginzburg IP, Semiletenko BG, Terpigor'ev VS, Uskov VN. Some singularities of supersonic underexpanded jet interaction with a plane obstacle. Journal of Engineering Physics. 1973;19(3):1081-84.

33. Powell A. The sound-producing oscillations of round underexpanded jets impinging on normal plates. The Journal of the Acoustical Society of America. 1988;83(2):515-33.

34. Chen K YYL, Modi V. Numerical simulation of oxidation effects in the laser cutting process. 1999; 15(11):835.

35. Man HC, Duan J, Yue TM. Analysis of the dynamic characteristics of gas flow inside a laser cut kerf under high cut-assist gas pressure. Journal of Physics D: Applied Physics. 1999;32(13):1469-77.

36. Pilch M, Erdman CA. Use of breakup time data and velocity history data to predict the maximum size of stable fragments for acceleration-induced breakup of a liquid drop. International Journal of Multiphase Flow. 1987;13(6):741-57.

37. Wierzba A. Deformation and breakup of liquid drops in a gas stream at nearly critical Weber numbers. Experiments in Fluids. 1990;9(1-2):59-64.

38. Joseph DD, Belanger J, Beavers GS. Breakup of a liquid drop suddenly exposed to a high-speed airstream. International Journal of Multiphase Flow. 1999;25(6-7):1263303.

39. Lobo L, Williams K, Tyrer J. The effect of laser processing parameters on the particulate generated during the cutting of thin mild steel sheet. Proceedings of the Institution of Mechanical Engineers, Part C: Journal of Mechanical Engineering Science. [10.1243/0954406021525016]. 2002;216(3):301-13.

40. C. J. Smithells, W. F. Gale and T. C. Totemeier, Smithells metals reference book, 8th ed. (Elsevier Butterworth-Heinemann, Amsterdam; Boston, 2004). 


\section{TABLES}

Table 1. The range of variation of the cutting parameters in the visualization experiments performed in continuous wave mode.

\begin{tabular}{lc}
\hline Processing parameter & Value \\
\hline Laser power $(\mathrm{W})$ & $800-1400$ \\
Cutting speed $(\mathrm{mm} / \mathrm{min})$ & $300-2000$ \\
Focal length $(\mathrm{mm})$ & 127 \\
Focus position $(\mathrm{mm})$ & Surface \\
Assist gas & Argon \\
Gas pressure $(\mathrm{bar})$ & $3-8$ \\
Nozzle diameter $(\mathrm{mm})$ & 2 \\
Stand-off distance $(\mathrm{mm})$ & $0.5-3$ \\
\hline
\end{tabular}


Table 2. Mean inclination of the cutting front as a function of the main processing parameters.

\begin{tabular}{ccccc}
\hline Laser power $(\mathbf{W})$ & $\begin{array}{c}\text { Cutting speed } \\
(\mathbf{m m} / \mathbf{m i n})\end{array}$ & $\begin{array}{c}\text { Linear energy } \\
\text { density } \\
(\mathbf{J} / \mathbf{m m})\end{array}$ & $\begin{array}{c}\mathbf{P}=\mathbf{3} \text { bar } \\
\left.\text { Angle } \mathbf{(}^{(}\right)\end{array}$ & $\begin{array}{c}\mathbf{P}=\mathbf{8} \text { bar } \\
\left.\text { Angle } \mathbf{(}^{(}\right)\end{array}$ \\
\hline 800 & 300 & 160 & 0 & 6.5 \\
& 500 & 96 & 6.9 & 7.5 \\
1,400 & 1,000 & 84 & 11.3 & 21.8 \\
& 1,400 & 60 & - & 30.4 \\
\hline
\end{tabular}


Table 3. Extension of the molten material flowing along the cut edge as a function of the processing parameters.

\begin{tabular}{cccc}
\hline Laser power $(\mathbf{W})$ & Cutting speed (mm/min) & $\begin{array}{c}\mathbf{P}=\mathbf{3} \mathbf{b a r} \\
\text { Area }\left(\mathbf{m m}^{\mathbf{2}}\right)\end{array}$ & $\begin{array}{c}\mathbf{P}=\mathbf{8} \mathbf{b a r} \\
\text { Area }\left(\mathbf{m m}^{\mathbf{2}}\right)\end{array}$ \\
\hline \multirow{2}{*}{800} & 300 & $5.80 \mathrm{~mm}^{2}$ & $3.94 \mathrm{~mm}^{2}$ \\
& 500 & $9.55 \mathrm{~mm}^{2}$ & $4.67 \mathrm{~mm}^{2}$ \\
1400 & 1000 & $10.10 \mathrm{~mm}^{2}$ & $5.86 \mathrm{~mm}^{2}$ \\
& 1400 & - & $8.4 \mathrm{~mm}^{2}$ \\
\hline
\end{tabular}


Table 4. Flow velocity of molten material along the cut edge as a function of the laser power and the assist gas pressure

\begin{tabular}{ccc}
\hline \multirow{2}{*}{ Laser Power $(\mathbf{W})$} & \multicolumn{2}{c}{$\mathbf{V}(\mathbf{m m} / \mathbf{s})$} \\
& $\mathbf{p}=\mathbf{3}$ bar & $\mathbf{p}=\mathbf{8}$ bar \\
\hline 800 & 90 & 110 \\
1400 & 700 & 1400 \\
\hline
\end{tabular}




\section{FIGURE CAPTIONS}

Figure 1. a) Experimental setup used for the visualization of the cutting process (view from above) and b) parameters evaluated in a typical recorded image.

Figure 2. a) Scheme showing the typical image of the cutting front and b) evolution of the cutting front geometry as a function of the cutting speed (Processing conditions: $P=1400 \mathrm{~W}$, p=8 bar).

Figure 3 Image sequence showing the ejection of molten material from the cutting front and along the cut edge (Processing conditions: $P=1400 \mathrm{~W}, v \mathrm{c}=1400 \mathrm{~mm} / \mathrm{min}$, Argon, $p=8 \mathrm{bar}$ ).

Figure 4 High speed video imaging showing the existence of regions with explosive evaporation probably due to boiling. (Processing conditions: $P=1400 \mathrm{~W}, \boldsymbol{v}_{c}=1000 \mathrm{~mm} / \mathbf{m i n}$, Argon, $p=3$ bar).

Figure 5 Examples of the MSD formation and weakeing for two stand-off distances; a) $z=1,5$ $\mathrm{mm}$ y b) $\mathrm{z}=3 \mathrm{~mm}$ (Processing conditions: $P=1400 \mathrm{~W}, v_{c}=1000 \mathrm{~mm} / \mathrm{min}$, Argon, $\boldsymbol{p}=8 \mathrm{bar}$ ).

Figure 6 Examples of displacement of the MSD by the plasma plume (Processing conditions: $P=1400 \mathrm{~W}, v_{c}=1000 \mathrm{~mm} / \mathrm{min}$, argon, $\left.p=8 \mathrm{bar}\right)$.

Figure 7 Example of the non-oscillatory character of the MSD when the laser radiation is interrupted (Processing conditions: $P=1400 \mathrm{~W}, v_{c}=1000 \mathrm{~mm} / \mathrm{min}$, argon, $p=8 \mathrm{bar}$ ).

Figure 8 Selected images of the cut front which reveals the difference in the flow direction as a function of the assist gas pressure: a) $\theta=50^{\circ}$ ( $p=3$ bar), b) $\theta=30^{\circ}$ ( $p=8$ bar) (Processing conditions: $P=1400 \mathrm{~W}, v_{c}=1000 \mathrm{~mm} / \mathrm{min}$, Argon).

Figure 9 Image sequence showing the formation of dross: a) formation of a droplet, b) growing, c) merging of the droplet with previous molten material d) complete merging and e) formation of another droplet (Processing conditions: $P=1400 \mathrm{~W}, v_{c}=1000 \mathrm{~mm} / \mathrm{min}$, Argon, $p=3 \mathrm{bar}$ ).

Figure 10 Image of the formation of drops of molten material behind the cutting front which are elongated by the assist gas (Processing conditions: $P=1400 \mathrm{~W}, v_{c}=1000 \mathrm{~mm} / \mathbf{m i n}$, Argon, $p=3$ bar).

Figure 11 Image sequence showing the rupture of molten material and the formation of small droplets in the lower part of the cutting front (Processing conditions: $P=1400 \mathrm{~W}, v_{c}=1400$ $\mathrm{mm} / \mathrm{min}$, Argon, $\mathrm{p}=8 \mathrm{bar}$ ).

Figure 12 Image showing the formation of a small particle due to the rupture of molten material (Processing conditions: $P=1400 \mathrm{~W}, v_{c}=500 \mathrm{~mm} / \mathrm{min}$, Argon, $p=8$ bar).

Figure 13 Typical aspect of the cut edge of workpiece of a) a glass and b) an aluminium-copper alloy using argon as assist gas. 


\section{FIGURES}

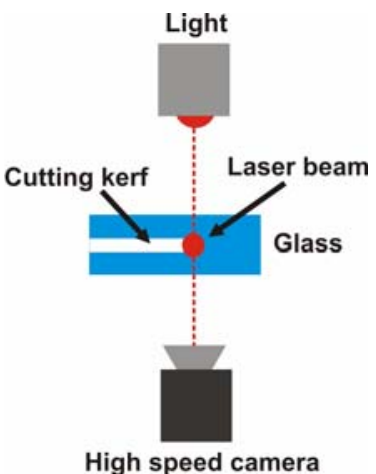

a

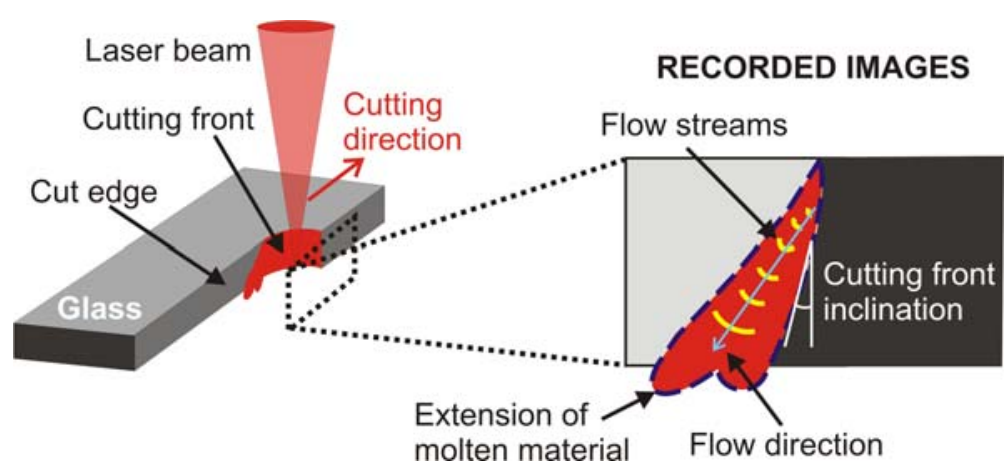

b

Figure 1. a) Experimental setup used for the visualization of the cutting process (view from above) and b) parameters evaluated in a typical recorded image. 


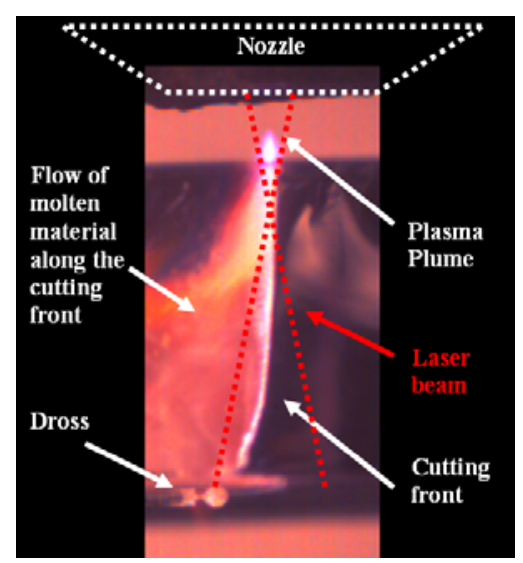

$\mathbf{a}$

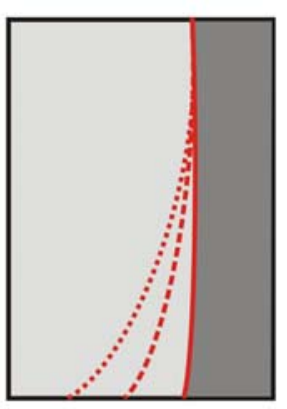

b
$-500 \mathrm{~mm} / \mathrm{min}$

-.-.. $1000 \mathrm{~mm} / \mathrm{min}$

........ $1400 \mathrm{~mm} / \mathrm{min}$

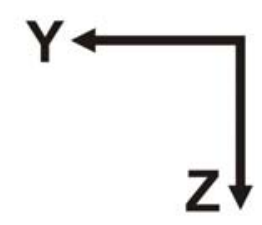

Figure 2. a) Scheme showing the typical image of the cutting front and b) evolution of the cutting front geometry as a function of the cutting speed (Processing conditions: $P=1400 \mathrm{~W}, \mathrm{p}=\mathbf{8} \mathrm{bar}$ ). 


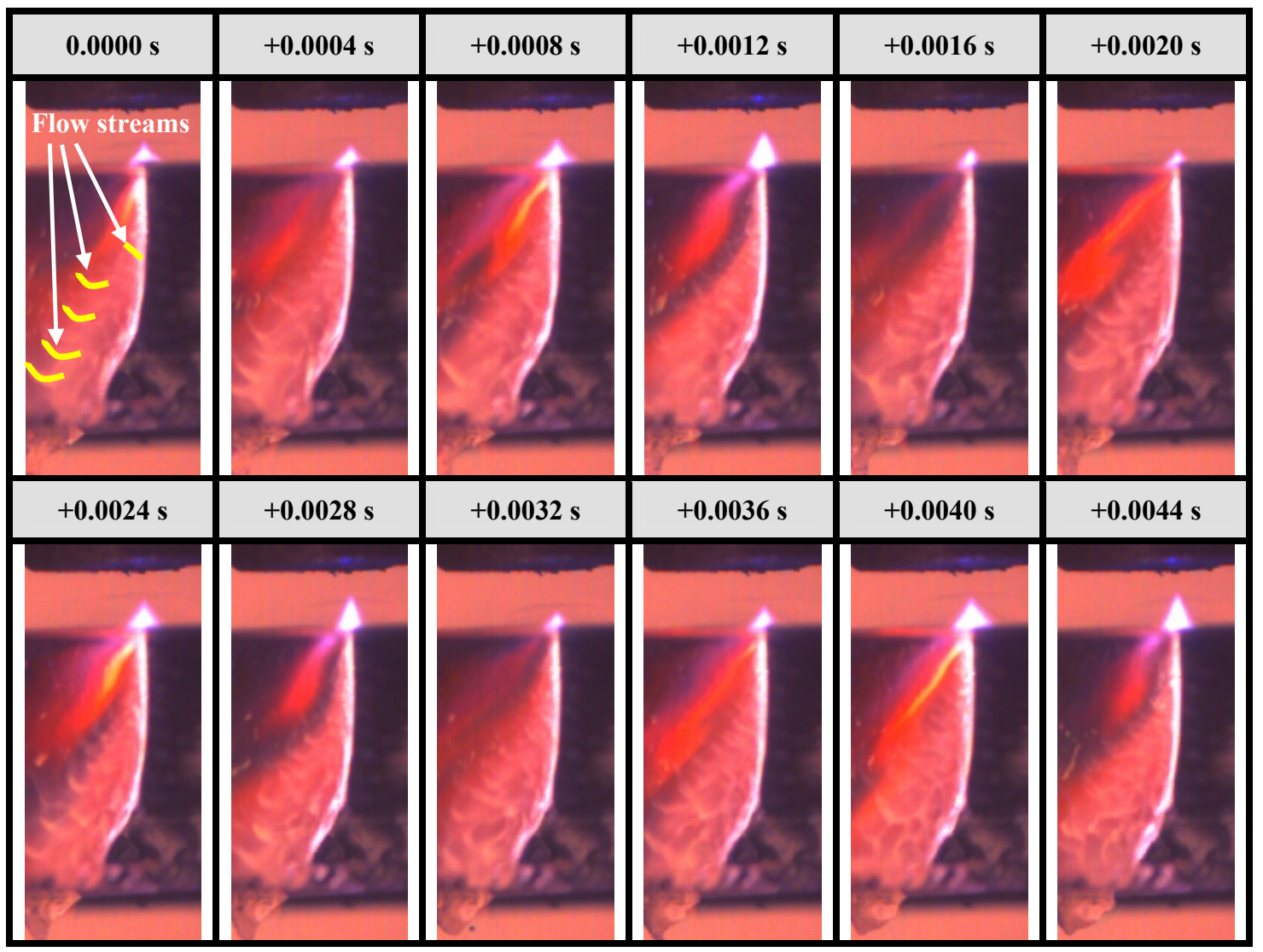

Figure 3 Image sequence showing the ejection of molten material from the cutting front and along the cut edge (Processing conditions: $P=1400 \mathrm{~W}, v \mathrm{c}=1400 \mathrm{~mm} / \mathrm{min}$, Argon, $\mathrm{p}=8 \mathrm{bar}$ ). (See also the video) 


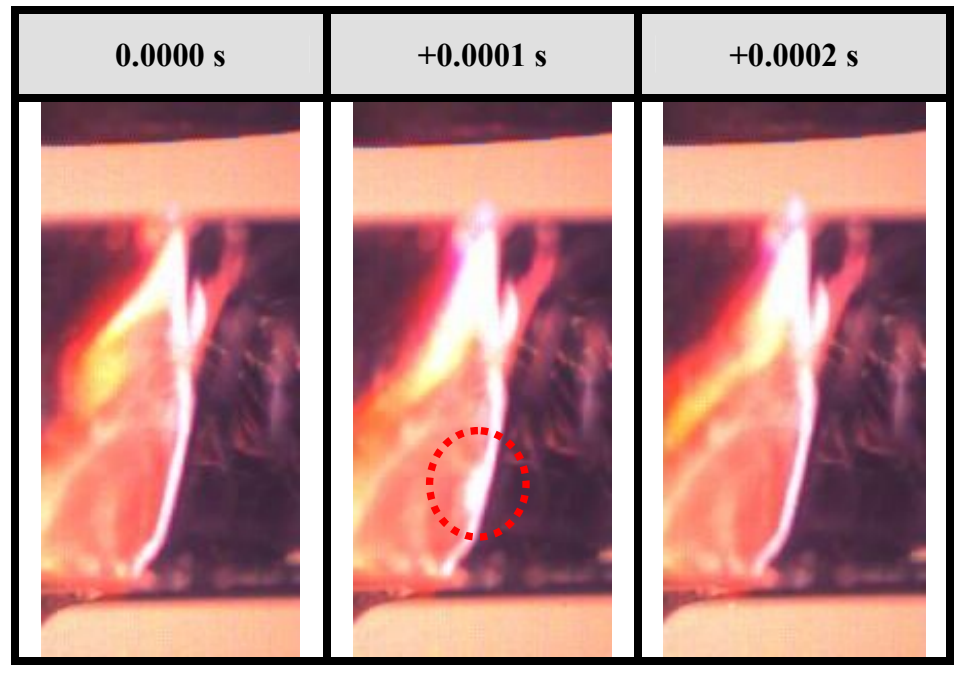

Figure 4 High speed video imaging showing the existence of regions with explosive evaporation probably due to boiling. (Processing conditions: $P=1400 \mathrm{~W}, v_{c}=1000 \mathrm{~mm} / \mathrm{min}$, Argon, $p=3 \mathrm{bar}$ ). 


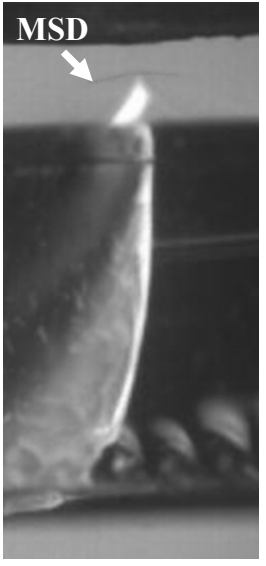

a

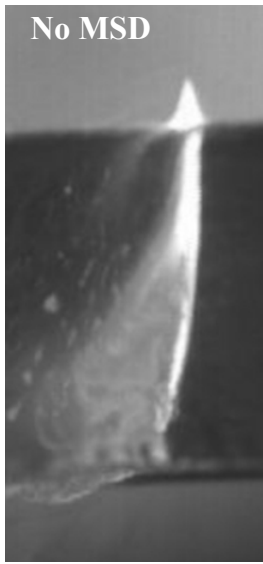

b

Figure 5 Examples of the MSD formation and weakeing for two stand-off distances; a) $z=1,5 \mathrm{~mm}$ y $b$ ) $\mathrm{z}=3 \mathrm{~mm}$ (Processing conditions: $P=1400 \mathrm{~W}, v_{c}=1000 \mathrm{~mm} / \mathrm{min}$, Argon, $p=8 \mathrm{bar}$ ). 


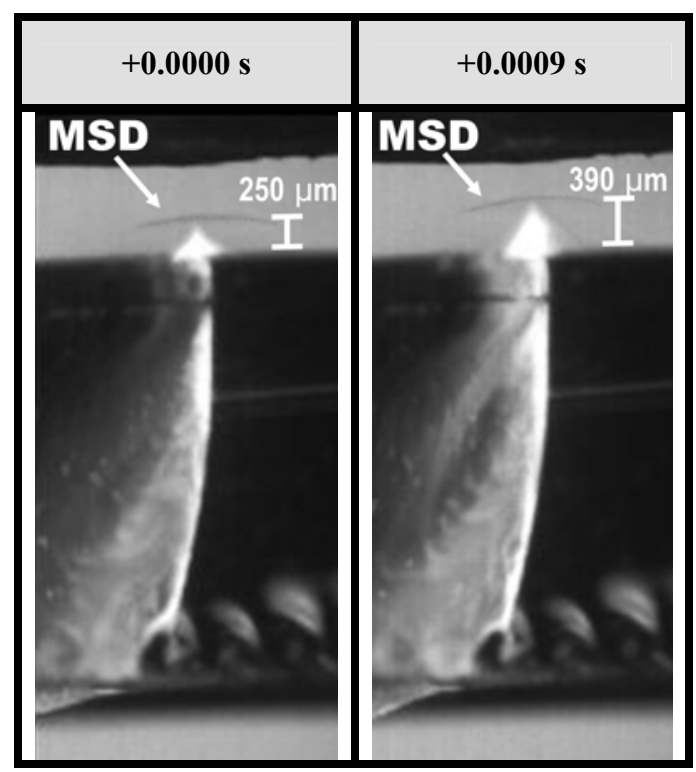

Figure 6 Examples of displacement of the MSD by the plasma plume (Processing conditions: $P=1400$ $W, v_{c}=1000 \mathrm{~mm} / \mathrm{min}$, argon, $p=8 \mathrm{bar}$ ). 


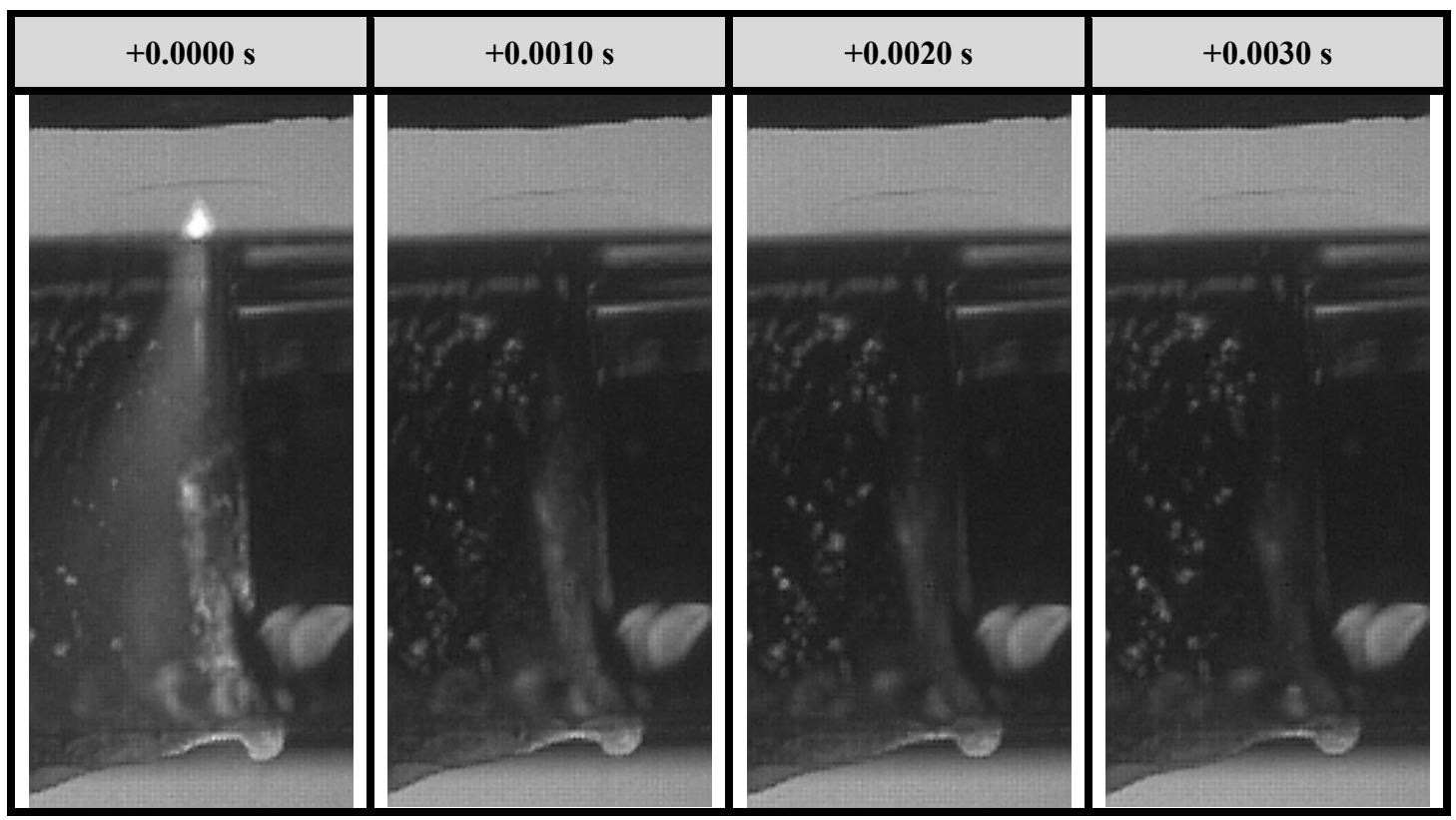

Figure 7 Example of the non-oscillatory character of the MSD when the laser radiation is interrupted (Processing conditions: $P=1400 \mathrm{~W}, v_{c}=1000 \mathrm{~mm} / \mathrm{min}$, argon, $p=8$ bar). 


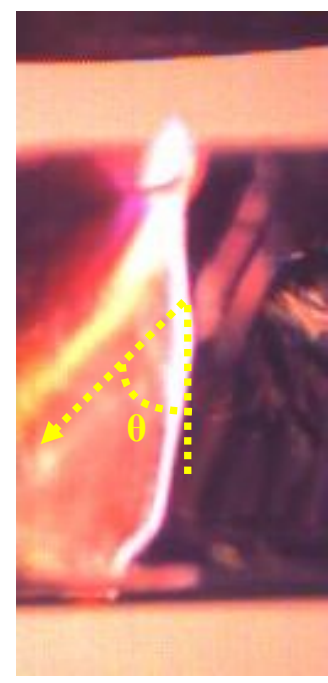

a

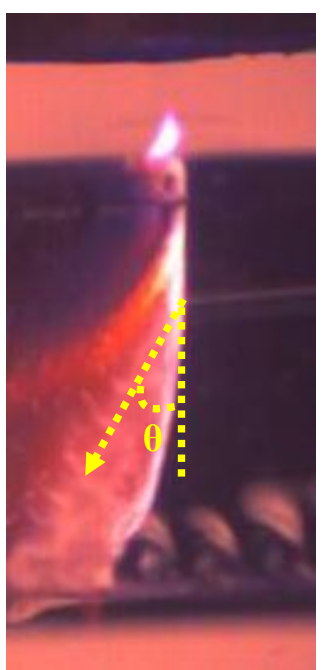

b

Figure 8 Selected images of the cut front which reveals the difference in the flow direction as a function of the assist gas pressure: a) $\theta=50^{\circ}\left(\mathrm{p}=3\right.$ bar), b) $\theta=30^{\circ}$ ( $\mathrm{p}=8$ bar) (Processing conditions: $\boldsymbol{P}=1400 \mathrm{~W}$, $v_{c}=1000 \mathrm{~mm} / \mathrm{min}$, Argon). 


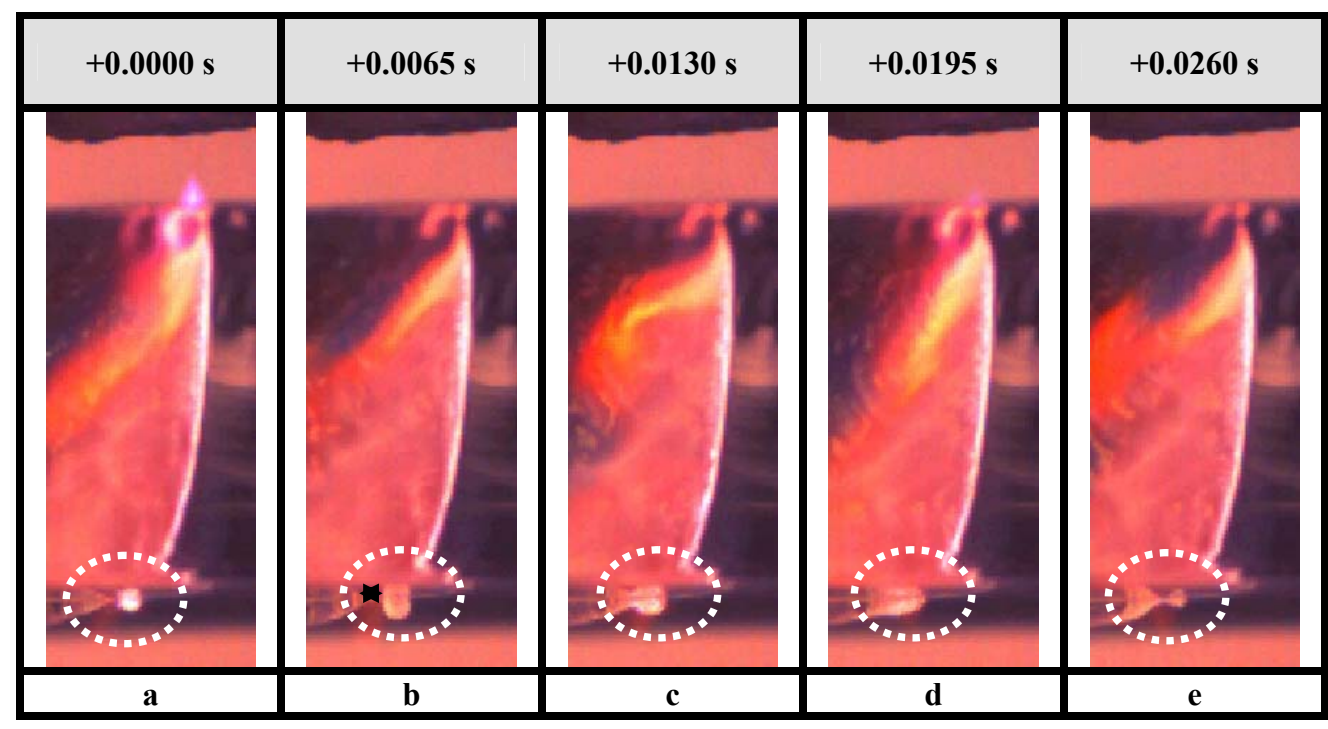

Figure 9 Image sequence showing the formation of dross: a) formation of a droplet, b) growing, c) merging of the droplet with previous molten material d) complete merging and e) formation of another droplet (Processing conditions: $P=1400 \mathrm{~W}, v_{c}=1000 \mathrm{~mm} / \mathrm{min}$, Argon, $p=3 \mathrm{bar}$ ). 


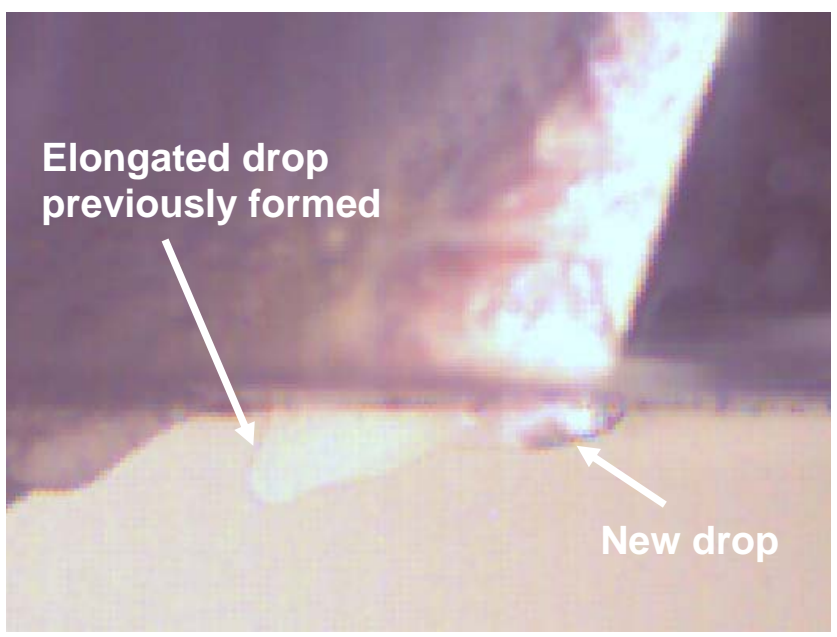

Figure 10 Image of the formation of drops of molten material behind the cutting front which are elongated by the assist gas (Processing conditions: $P=1400 \mathrm{~W}, v_{c}=1000 \mathrm{~mm} / \mathrm{min}$, Argon, $p=3 \mathrm{bar}$ ). 


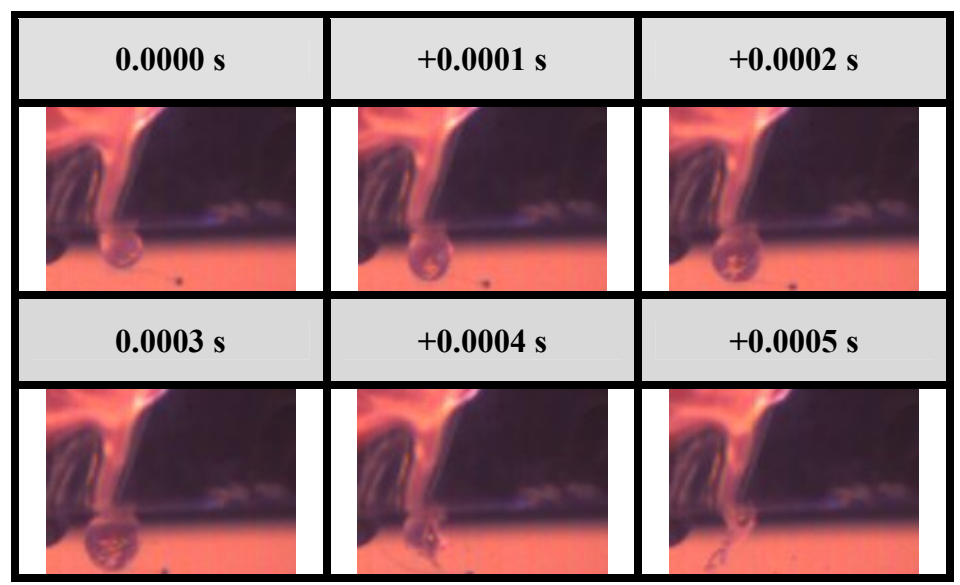

Figure 11 Image sequence showing the rupture of molten material and the formation of small droplets in the lower part of the cutting front (Processing conditions: $P=1400 \mathrm{~W}, v_{c}=1400 \mathrm{~mm} / \mathrm{min}$, Argon, $p=8$ bar). 


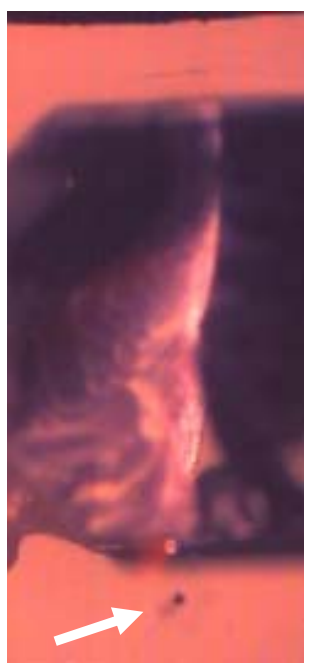

Figure 12 Image showing the formation of a small particle due to the rupture of molten material (Processing conditions: $P=1400 \mathrm{~W}, v_{c}=500 \mathrm{~mm} / \mathrm{min}$, Argon, $p=8 \mathrm{bar}$ ). 


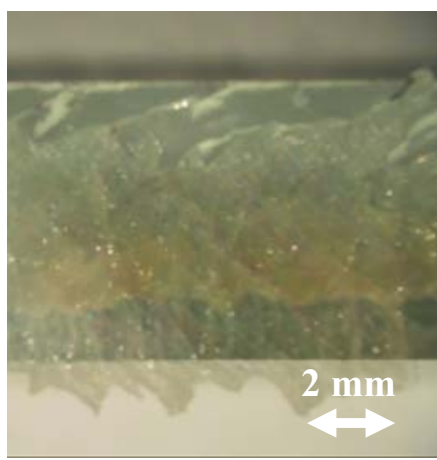

a

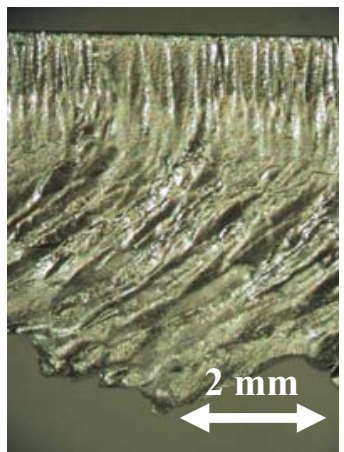

b

Figure 13 Typical aspect of the cut edge of of a) a glass plate and b) an aluminium-copper alloy plate using argon as assist gas. 